\title{
Accelerating the Energy Transition Through Serious Gaming: Testing Effects on Awareness, Knowledge and Efficacy Beliefs
}

\author{
Tania Ouariachi and Wim Elving \\ Professorship Communication, Behaviour \& the Sustainable Society. Center of Expertise Energy, \\ Hanze University of Applied Sciences, Zernikeplein, AS Groningen, The Netherlands. \\ t.ouariachi.peralta@pl.hanze.nl \\ w.j.l.elving@pl.hanze.nl \\ DOI: 10.34190/JEL.18.5.004
}

\begin{abstract}
To have sustainable societies, we need to accelerate the energy transition towards clean energy solutions, however, awareness and understanding of the process as well as intentions to change behaviors are still limited, especially among young people. An optimal balance considering the point of view from all parties involved is out of sight without a focus on social structures and a dialogue among all parties. In this context, universities have a critical role to play: these institutions build capacity through the development of new knowledge, new understanding and new insights, and can therefore provide effective solutions to complex societal challenges. In search of innovative approaches to reach young people, whose communicative paradigm has become more interactive and participatory, the use of serious gaming in formal education is gaining attention among scholars and practitioners: they can foster skills and abilities, contribute to content development of complex issues by integrating insights from different disciplines, and permit learning experiences that are not possible in real life. In this paper, we introduce "We-Energy Game", a serious game that address the urgency and complexities in the provision of affordable energy from renewable sources for an entire town. During the game, players negotiate, from their respective roles, which energy source they want to employ and on which location, with the goal to make a village or city energy neutral. Then, we present findings from a pretest and posttest completed by a hundred university students in The Netherlands to analyze the effects of the game on players awareness, understanding and efficacy beliefs. Results reveal positive outcomes on all variables.
\end{abstract}

Keywords: serious games, education, youth, sustainability, energy transition, effects

\section{Introduction}

In respond to the complex challenges introduced by the climate emergency, the European Union have set ambitious but urgent goals: to create a transition of the energy system by improving energy efficiency and increasing the share of renewable energy in ways that would be compatible with increasing competitiveness and security of supply, and reducing greenhouse gas emissions by $80-95 \%$ by 2050 , when compared to 1990 levels (EU, 2018). That means that involvement from all parties is necessary to reach those goals, from local governments to private sector and citizens; their awareness and understanding of the process is needed, however, communication and education efforts is an often-neglected pillar, especially among younger generations whose support is a significant driver in the short, medium and long term. In this context, universities have a critical role to play: these institutions build capacity through the development of new knowledge and insights and can therefore provide effective solutions to complex problems. They also produce a regular supply of highly educated, skilled people who will soon develop and implement solutions to present challenges. In words of Marie Sklodowska Curie: "nothing in life is to be feared, it is only to be understood. Now is the time to understand more, so that we may fear less" (EUA, 2017).

To reach young people, traditional communicative paradigms need to be revised towards new formats that facilitate a natural interaction between the person, the interface, and the environment. In search of innovative strategies, games are gaining attention among researchers and practitioners in higher education institutions, as a tool to raise understanding and encourage action on sustainability and energy transition. Games that are intended to fulfil a purpose, convey ideas and values, and sometimes, to influence the players' thoughts and actions in real life have received the name of Serious Games (Frasca, 2007). When used in formal education, these games can foster awareness, skills and abilities, contribute to content development, increase motivation and allow experiential learning.

In this paper we introduce "We-Energy Game" as an example, a serious game that address the urgency and complexities in the provision of affordable energy from renewable sources for an entire town. The game has been used among international students in higher education institutions in The Netherlands. In this paper we 
also present findings from a pretest and posttest to analyze the effects of the game on players' awareness, knowledge and efficacy beliefs.

\section{Games and education}

Until not long ago, video games have been linked to negative stereotypes and effects on gamers' physical and mental health. However, when playing takes place during a moderate length of time and the environment is adequate, they can also be seen a safe activity. Success of classical platforms such as Nintendo, through innovative games like Nintendo Wii Fit or Nintendo DS (e.g. Brain Training) show different methods in which digital games can have a positive impact on youth well-being. In this context, the Serious Games movement has emerged to use gaming technologies for communication, education or training purposes. The term invention has been attributed to Clark C. Abt in 1970, while the popularization has been assigned to the paper Serious Games: Improving Public Policy through Game-based Learning and Simulation by Ben Sawyer in 2002; later in 2007, the evidence of an established academic field became a fact with the foundation of The Serious Games Institute at Coventry University (Wilkinson 2016).

One of the reasons of the popularization of these tools are to meet the needs of the "interactive generation" (Aguaded-Gómez, 2011) or "digital natives" (Prensky, 2001). This generation of learners was born after the 1970s and has grown up surrounded by digital technology, entertainment media, social networks and two-way communication processes from a very young age. They usually engage in activities that have the capacity to reward them for effort and perseverance, "and as a result they expect the same level of reward from learning activities" (Felicia, 2009).

While youth shows a growing interest for games, especially digitally, educators are observing a declining motivation for school and difficulties to engage this generation to take part in traditional learning activities (Kemp, 2006). Specially topics like energy can be uninteresting for teenagers, so one solution has been the use entertainment media like games (Reeves et al., 2013), as it was done with birth control information in soap tv or nutrition information in radio dramas. Scholars have found out that games seem to have high intrinsic motivation factors, and this has been the basis for research conducted in the field of (video) games and education. One of the earliest works in the field of intrinsic motivation is attributed to Malone and Lepper (1987): they studied what makes computer games interesting and exciting, establishing a taxonomy of intrinsic motivation.

One of the main scholars in the field of games and education states that some of the learning principles that "good" games can incorporate are (Gee, 2003, 2004, 2005):

1. Identity: learning something requires the learner to play a role and take on a new identity which turns into becoming committed to the "new world" they are immersed.

2. Interaction: the game give reactions, placing feedback in the context of an interactive relationship between the player and the environment.

3. Production: players become producers by co-designing actions and taking decisions in the game.

4. Risk taking: players are encouraged to take risks, explore, and try new things, which the consequences of failure and negative feelings attributed to it.

5. Customization: players can usually, in one way or another, customize a game to fit with their learning styles by, for instance, having different levels of difficulty.

6. Agency: players can feel a real sense of control and ownership over what they are doing.

7. Well-order problems: when players are left free to explore and discover complex problem spaces, they can develop further creativity. Having different levels is a sign of the importance of arranging and organizing problems in the game.

8. Challenge and consolidation: games can offer challenging problems and then let players solve them until they have "automatized" their solutions; the new mastery is consolidated through repetition.

9. "Just in Time" and "On Demand": instead of providing many words like in books, games give verbal or visual information either when players need it or want it.

10. Situated meanings: games situate the meanings of words in terms of the actions, images, and dialogues they relate to.

11. System thinking: games encourage players to think about relationships and connections between causes and consequences. 
12. Cross-functional teams: when playing in teams, people are affiliated by their commitment to a common quest. This also makes the experience more fun and memorable.

However, in practice many education practitioners feel confused and lack guidance on how to evaluate quality of serious games that available for free online and on how to implement these games in class. When games are considered for instructional use, many factors must be weighed (Turkay et al., 2014). To bridge this gap, Ouariachi et al. (2019) developed an evaluation tool that presents a definition of quality and a scale of scores for each of the criteria, divided into five different categories (identification, narrative, contents, gameplay, and didactics), then the integration of the five dimensions provides quality scores that allow to determine the quality scenario of games (low quality, medium quality, and high quality). This tool can be used by teachers when deciding if certain serious games fit their needs to be implemented in class.

\section{Energy-related serious games}

Sustainability or energy literacy can play an important role in promoting political decisions and changes at the individual and collective levels; however, it is not easy or "attractive" to engage the public, especially young people, in these complex issues. Serious games make use of entertainment for educational purposes, facilitating the process in which players cultivate their knowledge and practice their skills in a subconscious way. Today, serious games are one of the growing areas in educational media; its market is expected to grow from 3.2 billion U.S. dollars in 2017, to 8.1 billion in 2022 (Statista, 2018).

Most of studies that map and explore serious games in the field of climate change or sustainability have found that mitigation is the main topic, understood by United Nations as efforts to reduce or prevent emission of greenhouse gases (Katsaliaki \& Mustafee, 2014; Ouariachi et al., 2017). Mitigation can be understood as using new technologies and renewable energies, making older equipment more energy efficient, or changing management practices or consumer behaviour; it can be as complex as a planning a new city or as a simple as improvements to a cook stove design. Concretely, serious games on energy issues have grown and diversified exponentially over the last years but, especially, these types of games have experienced most progress in an online format.

Different web platforms are available to the public and for free that serve as a repository of these types of games, such as Games4Sustainability or Gamepedia, targeting academics, trainers, NGOs, teachers, students, and anyone interested in this topic. Examples of energy related serious games include "Enercities", a game in which the player is faced with the challenge of developing an eco-friendly city dealing with issues such as pollution, energy shortages, and renewable energy. Players place buildings on a grid to grow their city. They need to balance energy sources, cash flow, and the city's economy, wellbeing, and environment. Another example is "WindMill Game", a strategy game about building wind farms to create clean energy profitably. Players fulfil a specified energy offset goal as quickly as possible by building turbines smartly, and research locations carefully for the best wind conditions, avoiding upsetting the local citizens by building turbines in undesirable places.

\section{Theoretical framework}

In the last decade, the interest in researching the potential of games beyond their motivational value for learning has brought an increasing number of papers and conferences proceedings (Turkay et al., 2014). According to Squire (2006), one of the emerging ideas is to think of games as "designed experiences in which participants learn through a grammar of doing and being". Under the same approach, Gee (2004) considers games as enablers of "situated language and learning", a view that relates to theories in situated cognition, which suggests that learning is tied to the authentic activity, context, and culture within which knowledge is developed.

The field of game-based learning and serious games in the education sector have also experienced an increasing number of studies related to effectiveness. Scholars have argued that serious games can be an effective tool to increase awareness and knowledge, but also to change people's attitudes and behaviors. The mechanism through which this process occurs is that "playing a game can lead to a state of flow or immersion where players are extremely concentrated and time passes unnoticed", which can lead to a higher awareness and understanding of relevant factors involved in the game (e.g. energy saving), and in effect, to a positive change in attitude which can subsequently trigger a change in behavior itself (Soekarjo \& van Oostendorp, 2015). Scientists have argued that "experientially derived knowledge" through vivid and concrete information is often 
more compelling to influence attitudes than "abstract knowledge" (Aronson, Wilson \& Akert, 2013). Regarding awareness, most studies have found positive changes (Van Pelt, 2015). Knowledge has been increased by players in five of the sixty games reviewed after playing them, however, evidence on changes in attitudes and behaviours is still contradictory (Soekarjo and van Oostendorp, 2015).

When addressing the extent to which environmental attitudes can predict environmental behaviors, Ajzen's Theory of Planned Behavior (1985) postulates that a positive attitude towards a particular behavior in combination with positive subjective norms and a higher degree of perceived control will likely positively influence a person's intention to perform that behavior, and increase the likelihood that the behavior will be performed. In relation to perceived control, a crucial concept is self-efficacy. According to Bandura's Social Cognitive Theory (1986a), perceived self-efficacy is the extent to which people believe that they are capable of doing specific tasks in order to achieve certain goals. Two common sources of self-efficacy are enactive experience (learning through direct experience) and observational learning (learning through observation of the experiences of others). Playing games can be considered a "mediated" enactive experience because it offers an environment to imitate behaviors and their consequences, and for Bandura (1986b), enactive experience is the more powerful mechanism to raise self-efficacy.

In the field of games, several empirical studies have been carried out examining the relationship between playing games, self-efficacy, and behavioral intentions or actual behavior change. On the one hand, Yang et al. (2016) found out that learners' behavioral intention was significantly improved after playing a game. Reeves et al. (2013) built a social game about energy use in a virtual home, and in a field test, smart meter data showed a significant decrease in electricity usage when comparing 30-day periods before and after playing. Using health games, Kato et al. (2008) study revealed that after playing a game there was significant increase of cancerrelated self-efficacy (significantly greater in game group vs. control group), and significant improvement of treatment adherence. In Peng's study (2009), self-efficacy and intention to eat healthier were significantly greater at post-test in the experimental group that played the game versus the control group who did not. On the other hand, scholars like Soekarjo and van Oostendorp (2015) suggest that limited empirical evidence is currently available to prove the effectiveness of games in attitude or behavior change: first of all, evidence of successful change in attitude after playing a persuasive game can only be found in five of sixty papers reviewed, and evidence of change in behavior in only three papers. Secondly, using a pretest-posttest design, they tested whether change in attitude was different for people playing the persuasive game EnerCities compared to a control condition where participants read a document with highly similar information, finding out no significant differences.

In order to raise awareness, improve knowledge and enhance self-efficacy beliefs, playing games shall provide an enjoyable experience (Lee, 2000). According to a research conducted by Zhonggen (2019), one of the main reasons for the effectiveness of serious games in education may be related with the impact of these games on learners' mood: effective serious games try to create a positive mood in order to encourage players' interest in gameplay, as well as better academic performances. Other studies put emphasizes on learners' previous attitudes as the main factor. In a research carried out by Sinatra et al. (2012), persuasive materials were used with students to change their attitudes as well as influence their willingness to change regarding global climate issues, finding out that students who have more favorable attitudes toward the idea of human-induced climate change are more likely to report a willingness to act. The study by Bell et al. (2016) reveals that adolescents who already actively engaged in reducing energy reported a significant increase in energy-saving behaviors as a consequence of participation in an online intervention based on implementation intentions, whereas those who were not already saving energy did not.

\section{Case study: We-Energy Game}

The We-Energy Game (developed at EnTranCe the Centre of Expertise Energy in Hanze University of Applied Sciences in Groningen, The Netherlands, under the project "From A to Sustainability") is a serious game aiming to create understanding on the urgency and the challenges in the provision of affordable energy from renewable sources for an entire town or city. The game can be played on board or on screen by a minimum of five players who take the roles of:

- Production: a project leader who needs to produce a certain amount of energy

- People: the citizens of the area where the game is played

- Planet: how green/clean is the energy production 
- Profit: how much profit is made by the different projects

- Balance: how easy to work with is the energy source for the network-operator

The exact calculations and effects of the different options are based upon scientific research and the latest insights. While playing, players negotiate from their respective roles which energy source they want to employ and on which location. Once agreement is reached, they place the icon that represents that energy source on the map and they check the consequences for each of the roles (production, people, planet, profit and balance).

Through playing the game, they will realize that without collaborating with the others, they will not be able to achieve their ultimate goal of creating a sustainable energy mix for their town or city. In the process, players also realize that there are many available solutions to reach an optimal balance, and that sustainability is not just a technical issue, but a social one as well. For example, even though there is great support for solar panels, the sun does not always shine, so other resources are needed; wind provides a lot of energy, but can also encounter protest by local residents; biomass could be a good solution, but its yields are less and its environmental footprint is greater.

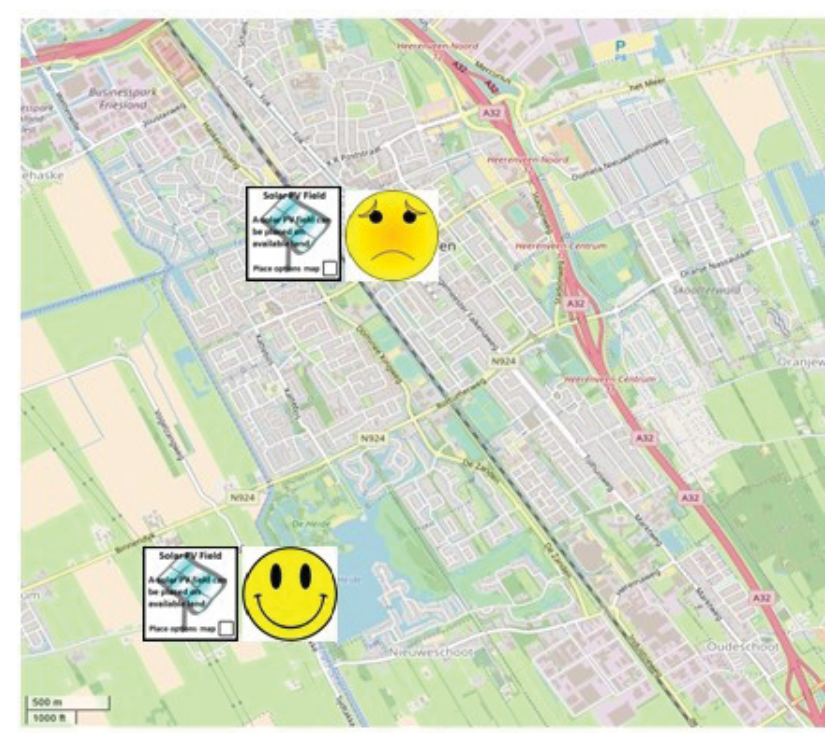

Figure 1: One of the location representations of We-Energy Game

The image above (Figure 1) is an example of locations represented in We-Energy Game, using real data based on own research and an open street map. In the Netherlands, population ranges from 500-5000 inhabitants in a village to 10,000-50,000 inhabitants in a populated area, like a city. The game uses four levels of difficulty by making use of four different maps in The Netherlands, allowing players to experience the challenges of making different towns with different populations sizes and urban structures energy neutral: Diever (goal: 25 points), Meppel (50 points), Assen (75 points), Emmen (100 points). The scores are also based on realistic effects of each variable and refer to the amount of energy, emissions, and impact. The game finishes when all roles reach the total score for the selected town, maintaining a positive balance. Therefore, the educational objective is to create understanding on the urgency and complexities once they are familiar with game mechanics in order to understand that the larger the locations are, the more challenging to achieve common goals and keep all roles satisfied are, and that the need of collaboration from all stakeholders is crucial to reach the goals. Additionally, although not the primary focus, the game hopes to influence positively on players' intentions to change behaviours on a later stage.

\subsection{Implementation of the game in class}

The We-Energy Game has been played by a variety of groups, such as energy cooperative members, business, municipality representatives and politicians, but also students. The game is suitable to be implemented in class for several reasons: on the one hand, it covers a variety of key competences and abilities. They can be integrated into 21st century skills-learning and innovation skills (critical thinking and problem solving), digital literacy skills, and career and life skills (adaptability, social interaction, accountability). On the other hand, the game is characterized to be interdisciplinary, which means that it can be used simultaneously for different disciplines, such as social studies or environmental studies, and to allow group work in class. 
The game has been implemented with students in higher education institutions, such as Hanze University of Applied Sciences. Students were Dutch and international and they belong to different disciplines: marketing, international communication, engineering, etc. The game session is facilitated by an expert on energy transition together with a teacher from the respective class. Before starting, students are introduced to the game goals and rules, then they are split into groups of five. The length of the gameplay is about 30 minutes when playing two different maps, and therefore two different levels. After playing the game, there is a debriefing session where information is shared and examined.

\subsection{Analysis of the effects}

\subsubsection{Methodology}

In search of evaluating the effects of the game on students, we conducted a pilot study using a pretest-posttest design research. Participants' awareness, understanding and efficacy beliefs are assessed by using a survey before playing the game and after playing the game, including as main questions (Table 1): how informed and what degree of urgency to act do they feel about the energy transition; how much do they believe energy transition is a social, economic or technical issue; how much do they agree that there are many available solutions to reach an optimal sustainable energy mix in their region; and how can they contribute, by themselves or with the community, to a sustainable energy transition in their region. Respondents are asked to rate those statements on a four-point and five-point Likert scale ranging from respectively 'not at all' to 'a lot'. They are also asked in an open question about the fun factor and learning points.

Table 1: Operationalizations of the variables in the study

\begin{tabular}{|l|l|l|}
\hline Variable & Indicator & Measurement \\
\hline Awareness & Information & Four-point Likert scale \\
\hline & Urgency & Five-point Likert scale \\
\hline Knowledge & Technical issue & Five-point Likert scale \\
\hline & Economic issue & Five-point Likert scale \\
\hline & Social issue & Five-point Likert scale \\
\hline Efficacy & Optimal mix for my region & Five-point Likert scale \\
\hline & Self-efficacy & Five-point Likert scale \\
\hline $\begin{array}{l}\text { Fun factor } \\
\text { New learning aspects }\end{array}$ & Collective-efficacy & Five-point Likert scale \\
\hline
\end{tabular}

Content validity of the instrument used is determined by a selection of dimensions explored by other authors on aspects of awareness, knowledge and efficacy beliefs. Items were compiled from similar previous studies and were based on topics present in the game. The researchers used Google Forms to compose and send the surveys online. The data was later transferred to the software SPSS Statistics in order to conduct statistical analysis such as t-test to compare scores pretest and posttest. We translated the students' names into numbers to guarantee their anonymity.

We also conducted a group discussion with a smaller group of students to understand their opinion about the game and to get more qualitative data about their interaction with the game. The discussion, facilitated by researchers just after playing the game, was aimed to be a collective exchange of ideas to share their opinions about the game and their main take-away. The sample of this study is composed by 101 bachelor (Dutch and international: German, Lithuanian, Czech, Azerbaijani, Bulgarian, British, Mexica, Chinese, Turkish, Ukrainian), who finished pre- and post-test, with a mean age of 20.4 years (18-25 years, 67,6\% female), at Hanze University of Applied Sciences.

\subsubsection{Findings}

From the survey, results reveal an increase in urgency and being informed about energy transition: after playing, majority of students feel more the urgency to take action $(t(100)=45,3 ; p<.001$; see Figure 2$)$ and significantly more informed about the energy transition $(t(100)=44.3 ; p<.001)$. 


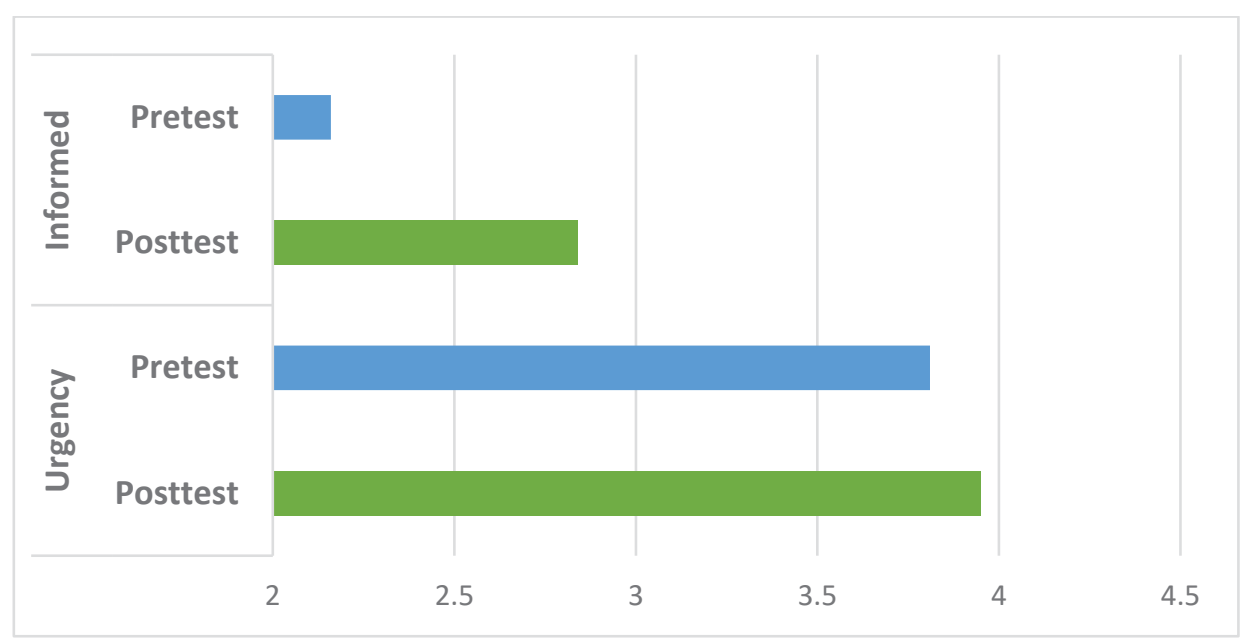

Figure 2: results on being informed and the urgency of the energy transition

When asked whether the students think the energy transition is a technical, economic or social issue and the extend to which they feel that their own region can find an optimal sustainable energy mix, we found in the posttest significant increases in both indicators (Table 2).

Table 2: one sample t-test statistics on whether the energy transition is a technical, economic or social issue, including the need to find an optimal regional optimal mix

\begin{tabular}{lccc}
\hline Variable & $\mathrm{t}$-value & degrees of freedom (df) & $\mathrm{p}$ \\
\hline Technical issue & 40,5 & 101 & $<.001$ \\
Economic issue & 53,2 & 101 & $<.001$ \\
Social issue & 44,8 & 101 & $<.001$ \\
Optimal regional & 40,4 & 101 & $<.001$ \\
\hline
\end{tabular}

The means on the issues and the optimal regional mix are displayed in Figure 3:

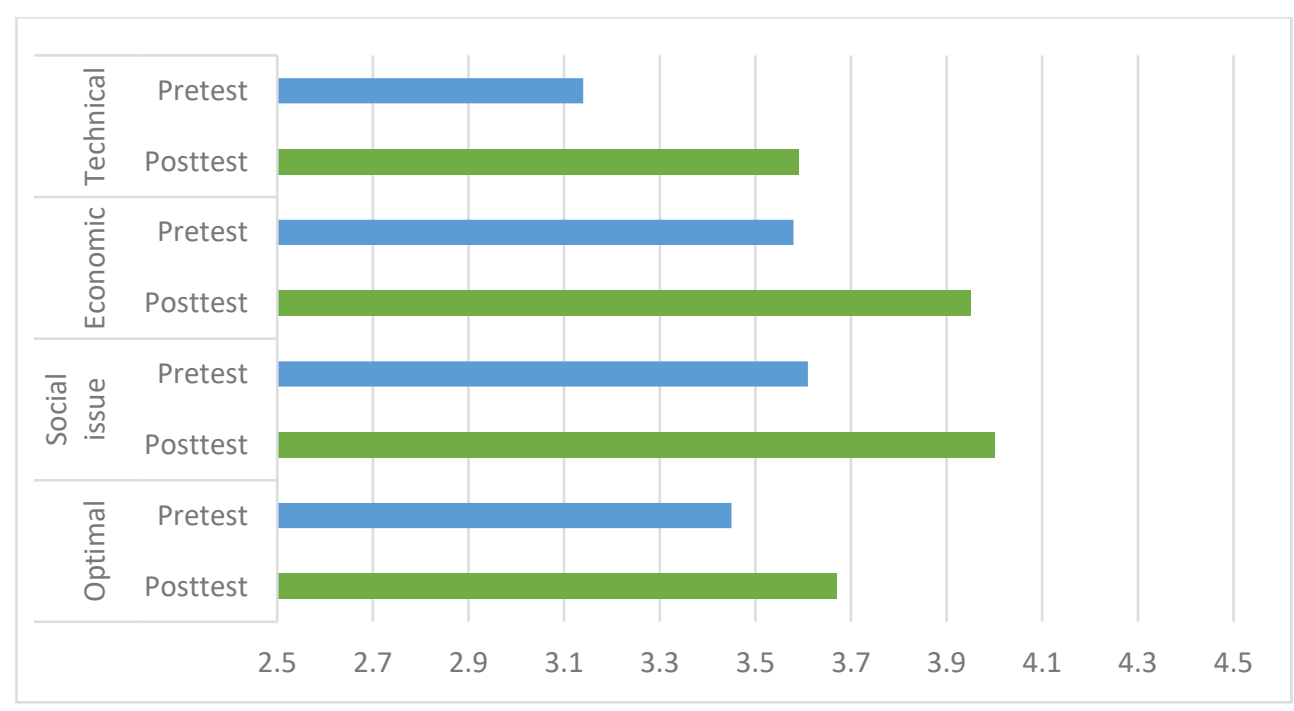

Figure 3: mean scores on the pre- and posttest on the social

The contribution individual students feel they can make (self-efficacy) was also significantly higher in the posttest compared to the pretest $(t(101)=34,6 ; p<.001)$ as well as the collective efficacy $(t(101)=35,7 ; p<.001)$. The means of self-efficacy and collective efficacy are displayed in Figure 4. 


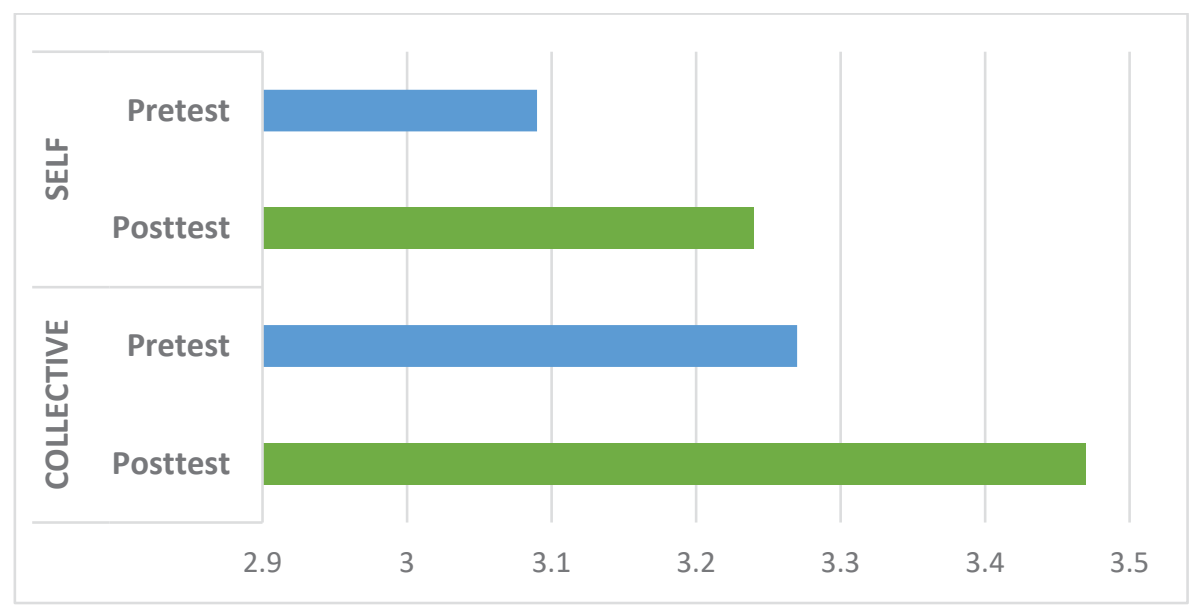

Figure 4: means in the pre- and posttest of self-efficacy and collective efficacy

The group discussion showed us that students perceive the game as fun and that they prefer to have this type of interactive practice rather than a traditional class characterized by a unidirectional transmission of information. After playing the game the students indicated an increase of the suitability of games for educational purposes $(\mathrm{t}(100)=41.0 ; \mathrm{p}<.001)$ and they indicated that their interest in the energy transition increased as well $(t(100)=39.0 ; p<001)$. The means of these two variables are presented in Figure 5.

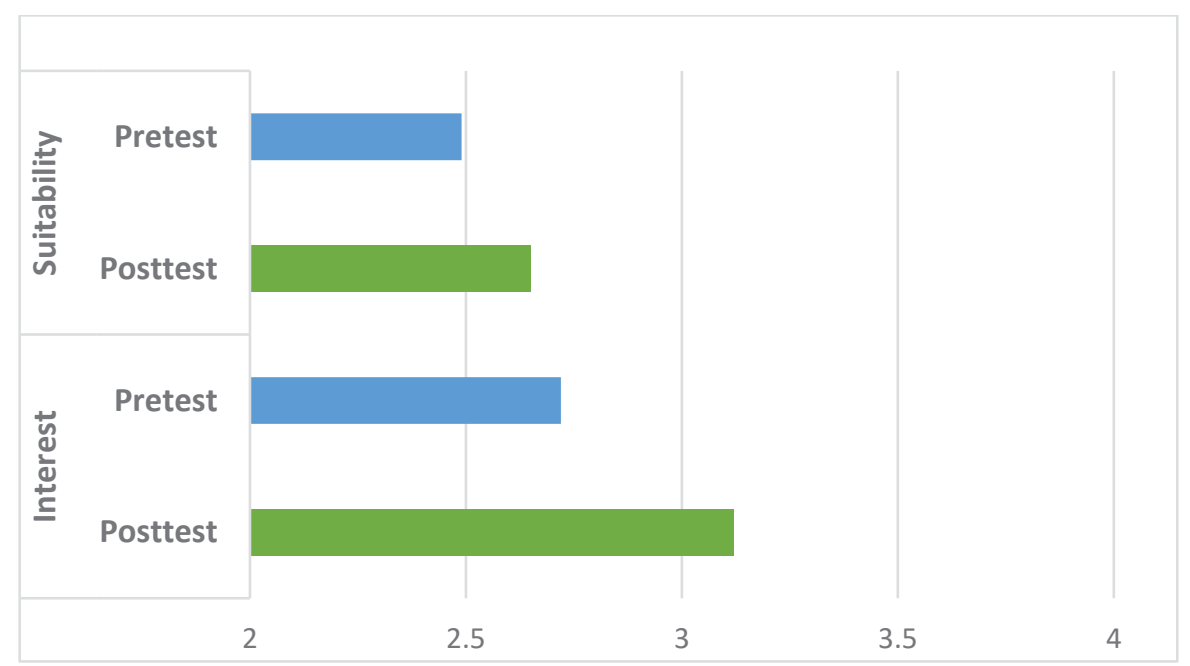

Figure 5: mean scores in pre- and posttest on the suitability of games for educational purposes and the interest in the energy transition before and after playing the game

However, the discussion also shows how educational games have still a long way to go to achieve the high levels of engagement of commercial games which present impressive graphics, more challenges and different types of interactive mechanics. The following table (Table 3) provides some examples of answers to the question was the game fun: 
Table 3: Opinions about the fun factor of the game

\begin{tabular}{|l|l|}
\hline Yes, because you had to be strategic & No, just initially. After I started playing I started thinking \\
Yes, because we were in control & about what can become priority to achieve our goal. Then \\
Yes, helping each other & I was thinking is it really hard to make such decisions \\
Yes, it was interactive and presented in a more fun way & No, too much calculation \\
Yes, nice team work, more fun than teaching style & No, there was no competition \\
Yes, because of the people I played it with & $50 / 50$ Fun for once \\
Yes, it's nice to try and get everybody to go as far as you can. & No, too much calculating and moving stuff around \\
it has strategy and creative thinking & No, it was very long \\
Yes, it was interesting and something different and we had to & \\
work like a team & \\
Yes, because we all had to work together and because it was & \\
Groningen and we recognized the parks & \\
Yes, it was really fun and interesting at the same time. It was \\
exciting to get an insight in the problematic situation and to \\
see what it actually means for the different parties Yes, \\
because we got to understand how to balance the different \\
resources and roles that are needed to achieve an arguable \\
sustainable environment
\end{tabular}

To the question 'what are your main learning points after playing the game', some of the answers are (Table 4):

Table 4: Opinions about the learning points of the game

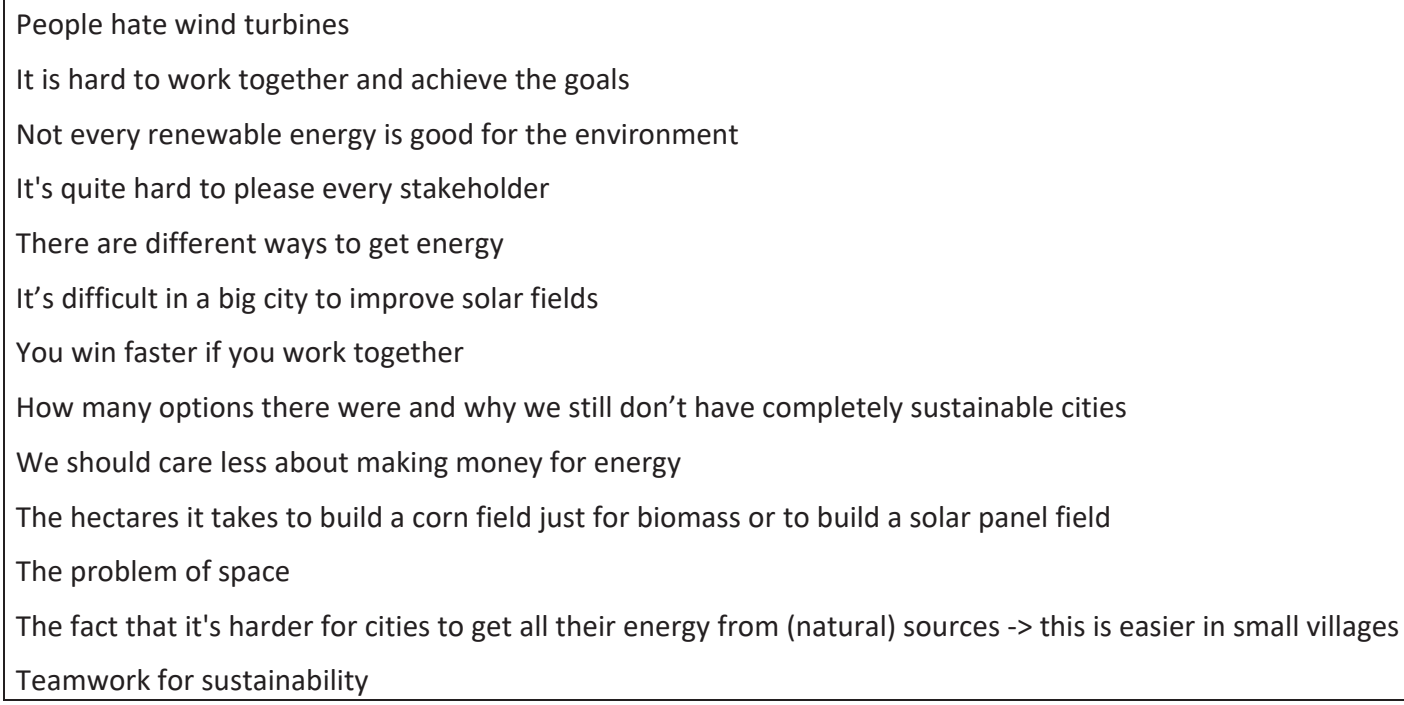

\section{Discussion and conclusions}

Using the We-Energy Game as a case study, this paper offers insights into the opportunities and challenges of using serious games in formal education, concretely in higher education institutions. The game has significantly contributed to raising awareness and understanding on the urgency and complexities of energy transition in an interactive, innovative and attractive way for young people. In accordance with other studies, serious games have potential in raising awareness and knowledge on complex issues -enhancing cognitive abilities, affect, and pleasant mood-, however, it remains to be seen to what extent these types of tools have also an impact on attitudes and behaviours. If we look at efficacy beliefs, considered here as a crucial antecedent of people intentions to change behaviours, in this case we observe that both self-efficacy and collective efficacy experience an increase after playing the game. Findings also reveal that the feeling of collective efficacy seems slightly higher than self-efficacy in the posttest. This might be related with the fact that the game encourages teamwork and dialogue among players to reach the goals. Through playing the game, they realize that without collaborating with the others, they will not be able to achieve their ultimate goal of creating a sustainable energy mix for their town or city. It is important to add that the game is developed for politicians and policy workers, and that students needed to jump in a situation that they normally would not so much have interest in. The results show that the game is excellent in raising awareness and raising the urgency of the Energy Transition. In addition, this research is considered a pilot study with a small sample of students, so we encourage researchers to further 
explore this field and conduct more empirical studies to test the effectiveness of this serious game or any other in improving awareness, knowledge and/or efficacy beliefs with larger samples of players.

What seems clearer is that most students perceive the game as a fun activity and usually prefer this type of interactive practices rather than traditional teaching methods. Several scholars have studied what are the possible factors of enjoyment. Ryan, Rigby and Przybylski (2006) use Self-Determination Theory (SDT) as a theoretical framework to explain that enjoying a behavior depends on the individuals' experience of autonomy, relatedness and competence. Crutzen, van't Riet and Short (2016) suggest narrative transportation (being away from the physical world and entering into the imaginary world presented in a story), relevance (selfidentification with characters), and competence. For Klimt (2003), competence is a key factor too. He states that in order to offer enjoyable experiences, the game should balance challenge and mastery in a careful way: "players should be able to achieve goals and perceive themselves as successful, but at the same time feel curiosity that is generated from the uncertainty of whether they will be able to cope with challenges as they arise". This analysis coincides with Csikszentmihalyi's (1990) flow theory, which postulates that most positive experiences result from mastering tasks that are not too easy and not too difficult.

In order to explore the impact of serious games on learning, different implications must be taken into account for educators and facilitators. From our experience, feedback, interaction among players, and debriefing. Zhonggen (2019), for instance, coincides in these three factors and adds backstory-production, realism, artificial intelligence-adaptivity in order to achieve success in learning. Other authors include the perceived usefulness of the game, ease of use, and goal clarity as indicators of satisfaction and effectiveness in use of serious games: when learners clearly predict the goals and ease of use, they tend to focus on the contents and enjoy themselves (Wang et al., 2017).

\section{References}

Aguaded-Gómez, I. 2011. Children and young people: the new interactive generations. Comunicar, 36(XVIII), pp. 7-8. doi:10.3916/C36-2011-01-01

Ajzen I. 1985. From intentions to actions: A theory of planned behavior. In Kuhl \& Beckman (Eds). Action-control: From cognition to behavior. Heidelberg: Springer, pp. 11-39.

Aronson E, Wilson TD, and Akert RM. 2013. Social Psychology. Upper Saddle River: Pearson Education.

Bandura, A. 1986a. Social foundations of thought and action: A social cognitive theory. Englewood Cliffs, NJ: Prentice-Hall.

Bandura, A. 1986b. The explanatory and predictive scope of self-efficacy theory. Journal of Clinical and Social Psychology, 4, pp. 359-373.

Bell, B. T., Toth, N., Little, L. and Smith, M.A. 2016. Planning to Save the Planet: Using an Online Intervention Based on Implementation Intentions to Change Adolescent Self-Reported Energy-Saving Behavior. Environment and Behavior, $48(8)$.

Crutzen, R., van't Riet, J., and Short, C. E. 2016. Enjoyment: A Conceptual Exploration and Overview of Experimental Evidence in the Context of Games for Health. Games for Health Journal, 5(1), pp. 15-20. doi:10.1089/g4h.2015.0059

Csikszentmihalyi, M. 1990. Flow: The Psychology of Optimal Experience. Journal of Leisure Research, 24(1), pp. 93-94.

European Union Commission. 2018. 2050 Energy Roadmap. Available online: https://ec.europa.eu/energy/en/ topics/energy-strategy-and-energy-union/2050-energy-strategy

European University Association (EUA). 2017. Energy Transition and the Future of Energy Research, Innovation and Education: An Action Agenda for European Universities, European University Association, Brussels.

Felicia, P. 2009. Digital Games in schools: A handbook for teachers. Brussels: European Schoolnet. Available online: http://gamesinschools.ning.com

Frasca, G. (2007) Play the Message: Play, Game and Video Game Rhetoric (Ph.D. Thesis), IT University of Copenhagen, Copenhagen.

Gee, J. P. 2004. Situated language and learning: A critique of traditional schooling. New York: Routledge.

Gee, J.P. 2003. What Video Games Have to Teach Us About Learning and Literacy. New York: Palgrave Macmillan.

good video games as learning machines

Gee, J.P. 2005. Learning by Design: good video games as learning machines. E-Learning, 2(1).

Kato, P.M., Cole, S.W., Bradlyn, A.S., and Pollock, B.H. 2008. A video game improves behavioral outcomes in adolescents and young adults with cancer: a randomized trial. Pediatrics, 122(2), e305-17. doi: 10.1542/peds.2007-3134.

Katsaliaki, K. and Mustafee, N. 2014. Edutainment for Sustainable Development: A survey of Games in the Field. Simul. Gaming, 6, pp 647-672.

Klimmt, C. 2003. Dimensions and determinants of the enjoyment of playing digital games: A three-level model. In: M. Copier and J. Raessens (Eds.): Level Up: Digital games research conference (pp. 246257). Utrecht: Utrecht University, Faculty of Arts.

Kemp, S. E. 2006. Dropout policies and trends for students with and without disabilities. Adolescence, 41(162), pp 235-250. Lee, W.R. 2000. Language teaching games and contests. Oxford: Oxford University Press. 
Malone, T. W., and Lepper, M. R. 1987. Making learning fun: A taxonomy of intrinsic motivations for learning. Aptitude, learning, and instruction, 3, pp 223-253.

Ouariachi, T., Galván-Pérez, L., Gutiérrez-Pérez, J., and Olvera-Lobo, M.D. 2019. A comparative analysis and quality assessment between Spanish and American serious games. The Journal of Communication and Media Studies, Vol. 4, No. 1, pp 33-42.

Ouariachi, T., Olvera-Lobo, M.D., and Gutiérrez-Pérez, J. 2017. Analyzing climate change communication through online games: development and application of validated criteria. Science Communication, 38(1), pp 10-44.

Prensky, M. 2001. Digital natives, digital immigrants. On the Horizon, 9(5), pp 1-6. doi:10.1108/10748120110424816

Reeves, B., Cummings, J.J., Scarborough, J.K., and Yeykelis, L. 2013. Increasing Energy Efficiency with Entertainment Media: An Experimental and Field Test of the Influence of a Social Game on Performance of Energy Behaviors. Environment and Behaviour, 20(10), pp 1-14.

Ryan, R.M., Rigby, C.S. and Przybylski, A. 2006. The Motivational Pull of Video Games: A Self-Determination Theory Approach. Motiv Emot. Doi: 10.1007/s11031-006-9051-8

Sinatra, G., Kardash, C., Taasoobshirazi, G., and Lombardi, D. 2012. Promoting attitude change and expressed willingness to take action toward climate change in college students. Instructional Science, 40(1), pp 1-17.

Soekarjo, M. and van Oostendorp, H. 2015. Measuring Effectiveness of Persuasive Games Using an Informative Control Condition. Int. J. Serious Games, 2, pp 37-56.

Squire, K. 2006. From content to context: Video games as designed experience. Educational Researcher, 35( 8), pp 19-29.

Statista. 2018. Game-Based Learning Market Revenue Worldwide in 2017 and 2022 (in Billion U.S. Dollars). Available online: https://www.statista.com/statistics/733616/game-based-learning-industry-revenueworld/

Turkay, S., Hoffman, D., Kinzer, C., Chantes, P. and Vicari, C. 2014. Toward Understanding the Potential of Games for Learning: Learning Theory, Game Design Characteristics, and Situating Video Games in Classrooms. Computers in the Schools, 31(1-2), pp 2-22.

Van Pelt, S.C. 2015. Communicating climate (change) uncertainties: Simulation games as boundary objects. Environ. Sci. Policy, 45, pp 41-52.

Wang, Y., Rajan, P, Sankar, C.S and Raju, P.K. 2017. Let them play: the impact of mechanics and dynamics of a serious game on student perceptions of learning engagement. IEEE Transactions on Learning Technologies, 10(4), pp 514-525.

Wilkinson, P. 2016. A brief history of serious games. In: Dörner et al. (Eds.): Entertainment Computing and Serious Games, LNCS 9970. Springer International Publishing, pp 17-41.

Yang, J.C., Lin, Y.L., and Liu, Y.C. 2017. Effects of locus of control on behavioral intention and learning performance of energy knowledge in game-based learning. Environmental Education Research, 23(6), pp 1-14.

Zhonggen, Y. 2019. A Meta-Analysis of Use of Serious Games in Education over a Decade. International Journal of Computer Games Technology, 797032, pp 1-8. 